\title{
LICENCIATURAS
}

\section{A ARGUMENTAÇÃO PERSUASIVA NA CONSTRUÇÃO DO DISCURSO CIENTÍFICO NAS AULAS DE QUÍMICA DO ENSINO MÉDIO}

\author{
ARGUMENTO PERSUASIVO EN LA CONSTRUCCION DEL DISCURSO \\ CIENTIFICICO EN LAS CLASES DE CHEMISTRY DE ALTA ESCUELA
}

\section{PERSUASIVE ARGUMENTATION IN THE CONSTRUCTION OF SCIENTIFIC DISCOURSE IN HIGH SCHOOL CHEMISTRY CLASSES}

\author{
Apresentação: Comunicação Oral \\ Maria Eduarda silva Torres ${ }^{1}$; Jeyseany de Fátima da Silva Rocha ${ }^{2}$; José Cláudio Soares da \\ silva $^{3}$; Magadã Marinho Rocha de Lira ${ }^{4}$
}

\section{DOI: $\underline{\text { https://doi.org/10.31692/2358-9728.VICOINTERPDVL.2019.0158 }}$}

\section{Resumo}

A ciência é uma área do conhecimento que requer uma serie de âmbitos para que se domine todas as suas particularidades, e com isso o professor como mediador do conhecimento busca implementar em suas aulas algumas maneiras que possam facilitar a condução deste conhecimento, fazendo o uso de várias estratégias pedagógicas como o uso da argumentação persuasiva, utilizada como recurso didático que permite a construção dos sentidos ligado aos termos científicos desta natureza. Diante disso, e entendendo a argumentação como processo que promove a aprendizagem da ciência proporcionado pelas estratégias de ensino que favorecem a argumentação através da adesão, este trabalho busca analisar a argumentação persuasiva no discurso do professor considerando as interações com os alunos, a partir do decorrer das aulas e dos conteúdos abordados na disciplina de química, produzido através de uma pesquisa com abordagem qualitativa do tipo estudo de caso, que foi realizada em uma turma do ensino Médio de um dos Instituto Federal de Pernambuco, a partir de observações e registros de 10 (dez) aulas de Química, tendo como objetivo examinar a argumentação persuasiva desenvolvida na construção do Discurso Científico do professor, delineando assim o processo argumentativo desenvolvido nas aulas de química; registrando todas as etapas e indicando alguns pontos da enunciação observada no desenvolvimeno das atividade ocorridas em sala, descrevendo situações e percepções relacionadas a linguagem do professor. Neste sentido, os resultados apresentados indicam que ao fazer o uso da argumentação persuasiva o docente consegue por adesão a sistematização das ideias dos conceitos apresentados em sala

\footnotetext{
${ }^{1}$ Licenciatura em Química, IFPE -Campus Vitória de Santo Antão, eduardatorres1999@gmai.com

${ }^{2}$ Licenciatura em Química, IFPE -Campus Vitória de Santo Antão, jeyseanyr@gmail.com Licenciatura em Química, IFPE -Campus Vitória de Santo Antão, claudiojoseclaudio4s@gmail.com

${ }^{4}$ Professora Doutora do Curso de Licenciatura em Química, IFPE - Campus Vitória de Santo Antão, magada.lira@vitoria.ifpe.edu.br
} 
de aula, favorecendo o desenvolvimento da aprendizagem do aluno, podendo ser considerada a importância da utilização dessas praticas argumentativas nas aulas de química como recurso que possibilita o delineamento do ensino de ciências como um facilitador do conhecimento.

Palavras-Chave: Ensino de Química, Argumentação, Persuasão.

\title{
Resumen
}

La ciencia es un área de conocimiento que requiere una serie de alcances para dominar todas sus particularidades, y con esto el maestro como mediador del conocimiento busca implementar en sus clases algunas formas que puedan facilitar la conducción de este Conocimiento, haciendo uso de diversas estrategias pedagógicas como el uso de argumentos persuasivos, utilizados como un recurso didáctico que permite la construcción de los sentidos vinculados a los términos científicos de esta naturaleza. Teniendo esto en cuenta, y entendiendo la argumentación como un proceso que promueve el aprendizaje de la ciencia proporcionada por las estrategias de enseñanza que favorecen la argumentación a través de la adhesión, este trabajo busca analizar la argumentación persuasiva en el discurso de Profesor considerando las interacciones con los estudiantes, desde el curso de las clases y los contenidos cubiertos en la disciplina de la química, producidos a través de una investigación con un enfoque cualitativo del tipo de caso, que se realizó en una clase de escuela secundaria de Uno de los Institutos Federales de Pernambuco, a partir de observaciones y registros de 10 (Diez) clases de Química, con el objetivo de examinar la argumentación persuasiva desarrollada en la construcción del discurso científico del profesor, esbozando el proceso Argumentativo desarrollado en clases de química; Registrar todos los pasos e indicar algunos puntos de la enunciación observados en el desarrollo de las actividades que ocurrieron en el aula, describiendo situaciones y percepciones relacionadas con el lenguaje del maestro. En este sentido, los resultados presentados indican que al hacer uso de argumentos persuasivos, el maestro logra la sistematización de las ideas de los conceptos presentados en el aula, favoreciendo el desarrollo del aprendizaje de los estudiantes, y mayo considerar se considera la importancia de utilizar estas prácticas argumentativas en las clases de química como un recurso que permite la delineación de la enseñanza de la ciencia como facilitador del conocimiento.

Palabras Clave: Enseñanza de Química, argumento, persuasión.

\begin{abstract}
Science is an area of knowledge that requires a series of scopes to dominate all its particularities, and with this the teacher as a mediator of knowledge seeks to implement in his classes some ways that can facilitate the conduction of this Knowledge, making use of various pedagogical strategies such as the use of persuasive argumentation, used as a didactic resource that allows the construction of the senses linked to the scientific terms of this nature. Given this, and understanding the argumentation as a process that promotes the learning of science provided by the teaching strategies that favor argumentation through adherence, this work seeks to analyze the persuasive argumentation in the discourse of Teacher considering the interactions with the students, from the course of the classes and the contents covered in the discipline of chemistry, produced through a research with a qualitative approach of the
\end{abstract}


case study type, which was performed in a class of high school of One of the Federal Institute of Pernambuco, from observations and records of 10 (Ten) Chemistry classes, aiming to examine the persuasive argumentation developed in the construction of the professor's scientific discourse, outlining the process Argumentative developed in chemistry classes; Recording all the steps and indicating some points of the enunciation observed in the development of the activities that occurred in the classroom, describing situations and perceptions related to the language of the teacher. In this sense, the results presented indicate that by making the use of persuasive argumentation, the teacher achieves the systematization of the ideas of the concepts presented in the classroom, favoring the development of student learning, and May be considered the importance of using these argumentative practices in chemistry classes as a resource that allows the delineation of science teaching as a facilitator of knowledge.

Keywords: Chemistry Teaching, argument, persuasion.

\section{Introdução}

Refletindo sobre o ensino de ciências e a importância da construção desse saber, faz-se relação entre o discurso cientifico do professor, e a introdução do aluno no meio cientifico através do seu aprendizado. A argumentação encontra-se presente em todo ato de linguagem explicitamente ou implicitamente apresentando uma relação dialógica entre a linguagem e as explicitações das estratégias do discurso, promovendo situações de comunicação entre o enunciador e o interlocutor, e neste sentido direcionamos nossos estudos para a importância e a necessidade dessas interações verbais, nas salas de aula de química, para tradução do discurso cientifico do professor.

A argumentação baseada na obra de Perelman e Olbrechts-Tyteca apresenta procedimentos apoiados em conjuntos de técnicas argumentativas, que constrói considerações e interações do discurso enunciado com o auditório pois "é em função de um auditório que qualquer argumentação se desenvolve” (PERELMEN e OLBRECHTS-TYTECA, 2014; p.8), diante disso defendem que a argumentação tem por finalidade a adesão de determinada ideia, que se da através da persuasão ou do convencimento, trazendo o convencer como uma maneira onde se utiliza provas racionais, enquanto o persuadir envolvendo aspectos mais subjetivos utilizando argumentos convincentes que levam o auditor a aceitação do conceito "propomo-nos chamar persuasiva a uma argumentação que pretende valer para um auditório particular e chamar convincente àquela que deveria obter a adesão de todo ser racional" (PERELMEN e OLBRECHTS-TYTECA, 2014, p. 32). 
A "linguagem é central à ciência, é o meio através do qual afirmações são feitas e desafiadas, métodos empíricos e dados são memorizados, e a história dos inquéritos se desenrolam" (CARLSEN, 2007, p. 67, tradução nossa), permitindo a construção de termos característicos, a ciência apresenta uma linguagem própria e ao estudar ciências é necessário que seja construída uma familiarização dos alunos com a linguagem particular que essa natureza possui, segundo Nascimento (2010) para conseguir que os estudantes passem a construir concepções fundamentais sobre está natureza, faz-se o uso de estratégias de ensino que se utilizem discussões, através do diálogo desenvolvido empregando argumentos e contra argumentações. Em vista disso, fazendo o uso de um sistema semântico da enunciação argumentativa e, por tanto, da persuasão (CORACINE, 1991; p.43) caracteriza o discurso cientifico como "guiado pelo desejo de persuadir o interlocutor-especialista através da evidência (provas, demonstrações cientificamente racionais) e das convenções argumentativas." com o intuito de tornar o discurso mais envolvente.

Nesta perspectiva, entendemos a argumentação como processo que promove a aprendizagem da ciência, proporcionada pelas estratégias de ensino, fazendo uso dos elementos da linguagem que "não é somente meio de comunicação, é também instrumento de ação sobre as mentes, meio de persuasão" (PERELMEN e OLBRECHTS-TYTECA, 2014; p.154), favorecendo a argumentação através da adesão. Sendo assim, a argumentação persuasiva torna-se o instrumento principal do professor nas aulas de química para a explanação de forma simplificada do seu discurso para facilitar a compreensão e adesão dos conhecimentos.

Concordando assim, com os pensamentos de Santos e Schnetzler (1996) que afirmam que a linguagem química deve ser, de forma que passem a interpretar os significados correspondentes as simbologias químicas vistas no seu cotidiano. Direcionando nosso estudo para o processo de interação promovido em sala de aula entre professores e estudantes, vinculado a produção do discurso argumentativo e persuasivo nas aulas de química do Ensino Médio, visando a condução do discurso e a estruturação de ideias apresentadas pelo professor que facilita a construção do conhecimento cientifico pelos estudantes.

Passamos então a concordar com o pensamento de Sasseron (2012), que considera o discurso argumentativo em sala de aula como dialógico, tendo por finalidade a compreensão do conteúdo abordado. 
Entendemos a argumentação como todo e qualquer discurso em que aluno e professor apresentam suas opiniões em aula, descrevendo ideias, apresentando hipóteses e evidências, justificando ações ou conclusões a que tenham chegado, explicando resultados alcançados. (SASSERON, 2012, p. 395)

Sendo assim, entendendo a argumentação como forma de coordenar os pensamentos para condução do enunciado nas aulas de química, utilizado como recurso didático que permite a construção dos sentidos ligado aos termos científicos desta natureza. Por tanto, objetivamos com este estudo observar a argumentação persuasiva desenvolvida na construção do discurso científico do professor, identificando as características desse discurso para construção do conhecimento nas aulas de ensino médio.

\section{Fundamentação Teórica}

"A ciência pode ser entendida como um processo dinâmico e não linear de proposição e avaliação de modelos científicos" (TEXEIRA, 2015, P.194) que podem também, ser entendidos como forma de compreensão de mundo que variam seus aspectos devido a sua abrangência e sua abordagem, as aulas de química adota neste sentido uma perspectiva que visa apresentar os fenômenos e transformações do mundo permitindo aos estudantes a construção de uma visão de mundo mais estruturado, pois "há necessidade de o aluno adquirir conhecimento mínimo de química para poder participar com maior fundamentação na sociedade atual.” (SANTOS e SCHNETZLER, 1996, p. 29).

Os saberes legitimamente sistematizados pela comunidade científica, possue variedade e mobilidade discursiva mediante os sentidos manifestos no discurso, sendo materializados nas formas estáveis de enunciados e adaptados para circulação e divulgação escolar (CICILLINI, 1997). O estudo dessa natureza decorre descrevendo, discutindo e problematizando as praticas do conhecimento cientifico, abordando sua visão e linguagem própria.

No ensino das ciências os alunos precisam ser introduzidos nessa linguagem cientifica de representação, descrição e compreensão do mundo como uma oportunidade de criar nova maneira de vê-lo, e para isso os argumentos em salas de aula são essenciais pra o uso coerente dessa linguagem. Mendonça concordando com a ideia de outros autores, evidencia que 
A argumentação é inerente à ciência devido: (i) à necessidade intrínseca de justificar e julgar a adequação de modelos e teorias de acordo com os conhecimentos e evidências disponíveis; e (ii) ao caráter social da ciência, em que os construtos gerados pelos cientistas estão abertos à discussão e refutações pela comunidade científica. (MENDONÇA, 2013,p.196)

A construção de conhecimentos científicos, a partir da adesão (convencimento/persuasão) a respeito de elementos próprios da linguagem científica, leva-nos a direcionar nosso olhar investigativo partindo da premissa de que "enunciar é argumentar" (GOULART, 2007, p. 93) tendo como horizonte as seguintes premissas citadas pela autora

(1) A argumentatividade da linguagem é inerente ao princípio dialógico, já que todo enunciado é produzido intencionalmente na direção do Outro, no movimento da interminável cadeia de enunciações. (2) Enunciar é agir sobre o Outro, isto é, enunciar extrapola a ideia de compreender e responder enunciados.

Jiménez-Aleixandre e Brocos (2015) defendem a argumentação caracterizada em duas relevantes didática das ciências: avaliação de conhecimentos à luz das provas disponíveis; e persuasão da audiência. Apontar estratégias de estimulo para a argumentação neste ambiente prioriza assim "como forma de desenvolver o raciocínio, o pensamento crítico, a metacognição e a compreensão sobre a natureza da ciência nas salas de aula" (SCARPA, 2015).

A persuasão é defendida por Perelman e Olbrechts-Tyteca (2014) como finalidade última da argumentação, entretanto distinguem o persuadir do convencer, o convencer busca a aceitação das ideias usando logicas racionais e o persuadir diz respeito a busca da adesão através da subjetividade, Coracine (1991) relaciona a subjetividade como uma das características principal do discurso científico, como a colocação de problemas em discussões e da função do aluno como ser ativo no seu processo de aprendizagem, pois "A argumentação como persuasão implica em movimentos retóricos empregados na fala e na escrita com o objetivo de ponderar e dar forças às conclusões visando o convencimento" (MENDONÇA, et al, 2013; p.197). Dessa forma a persuasão está inserida na argumentação das práticas envolvidas na construção dos conhecimentos, onde as afirmações terão um grau maior de tenacidade através das conexões de justificativas das afirmações atribuindo um caráter atrativo ao conhecimento e tornando o discurso cientifico mais envolvente. 
"Persuadir vincula-se a alcançar a adesão atingindo a vontade, portanto dirige-se a um auditório particular, com características peculiares e momentos determinados" (LIRA, 2017; p.20), através disso, entendemos está argumentação como processo de aprendizagem que promove a construção dos conhecimentos científicos em sala de aula de uma forma usual.

As aulas de Química, na perspectiva de ciência adotada neste estudo, visam à compreensão dos fenômenos e transformações do mundo mediante um olhar abrangente e integrado dos conhecimentos científicos, permitindo a construção de uma visão de mundo menos fragmentada e mais articulada, pois a química está presente em todos os âmbitos da nossa vida e precisamos ter sensibilidade e desenvolver capacidade para reconhecer a sua presença e importância na formação do ser humano, natural e social.

\section{Metodologia}

Este estudo descreve uma pesquisa qualitativa do tipo estudo de caso por se tratar da analise de dados investigativos, desenvolvido em uma turma do $1^{\circ}$ ano do ensino médio, com aproximadamente 30 alunos de idade entre 14 e 16 anos do IFPE - Campus Vitória de Santo antão no período do segundo semestre do ano de 2018.

Como o foco de nossa pesquisa é analise do discurso oral, a coleta de dados para serem analisados de acordo com o objetivo deste presente trabalho se deu a observação de 10 (dez) aulas de química, o material para análise foi construído mediante o desenvolvimento de atividades relacionadas as unidades temáticas abordados em sala.

Tabela 1: Unidades temáticas abordados em sala

\begin{tabular}{|c|c|c|}
\hline Aulas & Conteúdos Abordados & Período/Tempo \\
\hline 1 e 2 & $\begin{array}{c}\text { Interações atômicas e } \\
\text { moleculares }\end{array}$ & $90 \mathrm{~min}$ \\
\hline 3 e 4 & $\begin{array}{c}\text { Cálculos do número de } \\
\text { oxidação }\end{array}$ & $90 \mathrm{~min}$ \\
\hline 4 e 5 & Química e quantidades & $90 \mathrm{~min}$ \\
\hline 5 e 6 & Equações químicas & \\
\hline
\end{tabular}




\begin{tabular}{|c|c|c|}
\hline 7 e 8 & Coeficientes estequiométricos & $90 \mathrm{~min}$ \\
\hline 9 e 10 & Funções inorgânicas & $90 \mathrm{~min}$ \\
\hline
\end{tabular}

Fonte: Própria (2019)

Ao observar as aulas foram feitos as anotações, registradas através da construção de diários de campo elaborados a partir de anotações detalhadas e áudio-gravações das aulas, registrando todas as etapas e indicando os discursos observados no desenvolvimento das atividade ocorridas em sala, descrevendo situações e percepções relacionadas a linguagem do professor, a interação com os alunos, descrevendo também as práticas argumentativas desenvolvidas nas aulas de química, analisando a locução do docente e evidenciando a persuasão estabelecidas.

Fluxograma 1: Esquematização da sequência seguida para análise dos dados.

Observação das aulas de Química (10 aulas de exposição)

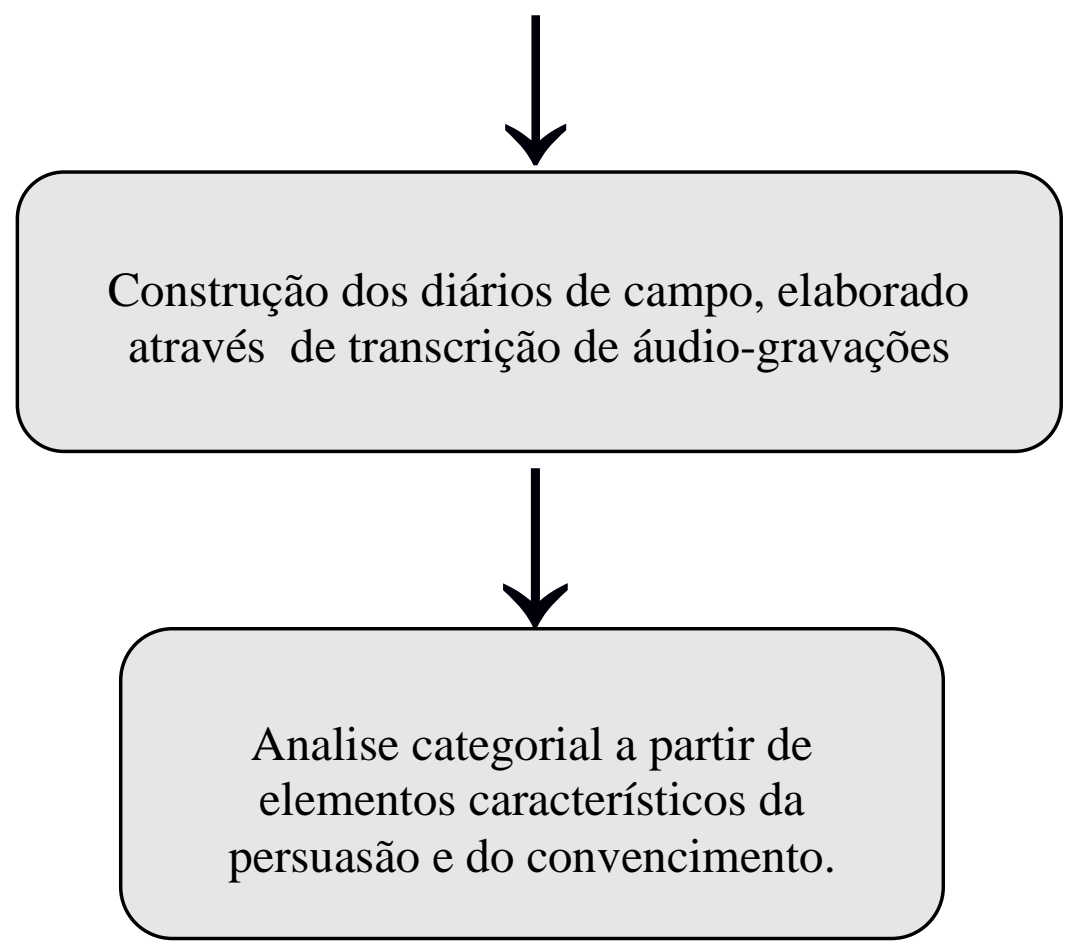

Fonte: Própria (2019) 
A partir das falas transcritas selecionamos alguns dos episódios analisado, considerados como momento privilegiado para a argumentação do professor e dos alunos, apresentando desde a fase de discussão até a de compreensão e adesão do conteúdo proposto por meio dos alunos, apontando o posicionamento dos mesmos e os possíveis fatores que influenciam na facilitação da compreensão e da tradução do discurso cientifico das aulas de química.

\section{Resultados e Discussão}

Durante o decorrer de todas as dez aulas observadas neste período, o conteúdo foi apresentado pelo professor de forma direta em buscava do convencimento em relação aos alunos a respeito do conteúdo abordado, exercitando a persuasão do discurso científico (CORACINI, 1991). Diante disso, observamos e destacamos alguns pontos do discurso desenvolvido pelo professor, fazendo o recorte de algumas aulas onde podemos identificar as estratégias de argumentação através da persuasão utilizada pelo docente. Como primeiro ponto utilizado pelo docente percebemos a contextualização e interação, como quando em uma das aula de oxirredução ele diz "Carros para se movimentar... Funciona sem o combustivel?" fazendo com que os alunos interajam em sua aula respondendo sua pergunta levando-os a uma busca pelo conhecimento, para poder continuar sua explicação "Primeiro você liga a ignição e assim inicia-se o processo, que causa a explosão da reação química do combustível que gera a energia que faz com que o carro se movimente [...]”, então explicou o conceito mostrando no quadro algumas equação química como por exemplo do álcool com o oxigênio, mostrando a perda e ganha dos elétrons, e também a sua distribuição eletrônica. Quando o professor faz uso da problematização buscando a interação de seus alunos, entendese como uma busca da dialógica baseada na atividade pratica de persuadir os alunos a admitirem suas explicações, a criarem suas hipóteses, isso pode ser percebido nesta mesma aula enquanto o professor montava as equações químicas no quadro e falava da oxidação, um dos alunos criou sua hipótese e fez sua pergunta "Então tudo que está exposto ao oxigênio pode ser oxidado?" o aluno percebeu isso ao ver as equações mostradas pelo professor, disse que percebeu por ter visto que todas possuíam o oxigênio, sua hipótese estava coerente, e para que os alunos aderissem este pensamento utilizou um exemplo do cotidiano, falou " $A$ salada de fruta que nós fazemos ou compramos, se deixarmos exposta as frutas começam a escurecer, e isso são as frutas oxidando". 
A aproximação com o cotidiano é mais um dos pontos observados, em uma aula sobre química e quantidades, por exemplo, Iniciou explicando que o conteúdo era sobre a relação entre a química e as diversas quantidades nela existente.

Professor: "Precisamos de medidas para tudo, para pagar passagem de um ônibus quando vamos viajar, para fazer um bolo... e para isso sempre temos um padrão, como por exemplo o padrão de massa em gramas e seus respectivos múltiplos". Disse "Para medirmos nossa massa a gente utiliza a balança normal de farmácia e não aquela de macaxeira da feira, mas quem disse que aqueles pesos que pesam a macaxeira tem mesmo $1 \mathrm{Kg}$ ? Os padrões! As referencias! Isso é que da origem ao SI que vocês conhecem muito bem da física".

Neste trecho da fala do professor percebe-se que além da associação com coisas cotidianas e rotineiras o professor também faz ligação do conteúdo de química com o conteúdo de outras disciplinas, o que auxilia na associação para os alunos, continuando sua aula e reforçando a ideia de que se precisa de um padrão para se ter uma medida usou exemplo do aluno mais inquieto da turma como padrão para o menos inquieto, fazendo com que os alunos interagissem mais na aula, e logo complementou com "Mas que padrões utilizamos na química?". Neste fragmento do discurso do docente identifica-se estratégias argumentativas com o objetivo de prender sua atenção, usando a própria turma como exemplo, organizando os pensamentos dos alunos para as informações do conteúdo que acabaram de lhe serem apresentadas, "como forma de conquistar a confiança e a simpatia do interlocutor a fim de persuadi-lo" (MASSMANN, 2011 p.376) utilizando de argumentos fundamentados em emoções que vincula-se a vivencia do publico de alunos.

Abaixo destacamos alguns fragmentos da interação entre o professor e seus alunos onde se encontra essa aproximação do cotidiano que pode facilitar a adesão do conteúdo e dos conceitos abordados.

O professor desenhou no quadro um círculo e o dividiu em 12 pedaços deixando-o com aparência de uma pizza, "Imaginem que isso seria o átomo do carbono e ele fosse dividido em 12 partes iguais" falou o professor, explicando que no padrão de quantidade de massa em relação ao carbono 12, cada parte (1/12) equivalia a 1unidade de carbono (1U).

Professor: "Se cada parte (1/12) equivale a $1 U$ do átomo de carbono, então quantas partículas eu tenho ao total?",

Fez está pergunta tentando explicar sobre os próton e nêutrons do núcleo do carbono por umas 3 vezes, mas os alunos não conseguiam entender. Para que houvesse o entendimento o 
professor explicou de forma mais simplificada fazendo uso de termos mais simples e de exemplos do cotidiano.

Professor: "Imagine que este gráfico em forma da pizza é uma pizza de verdade em que metade dela é de calabresa e metade mozarela, assim, cada uma parte (1/12) equivale a 1 fatia, quantas fatias de pizza eu tenho no total?"

Alunos: "Doze”

Professor: "E de calabresa?"

Alunos: "Seis"

Professor: "E de Mozarela?”

Alunos: "Seis também"

Professor: "Agora entenda que a pizza é o átomo de carbono, onde a parte de calabresa da pizza seriam os nêutrons e a parte de mozarela os prótons, cada uma parte (1/2) equivale a Iu então, quantas partículas eu tenho no total?"

Alunos: "Doze?"

Professor: "Isso, doze! E qual a quantidade de prótons e qual a quantidade de neutros?"

Alunos: "Seis!"

Percebemos então o uso de uma conduta suave do discurso, já que o assunto tem uma característica mais abstrata, então o professor buscou fazer uso de termos mais simples que seguisse uma logica e fizesse com que a turma abstraísse o conteúdo abordado. Como em outra aula, falando sobre mol e equação química, o professor revisou um pouco do assunto para relembrar aos alunos que a equação química é uma tradução de algo microscópico, que a seta da reação química mostra o sentido de transformação, falou - "Como no transito, que as placas mostram em qual sentido podemos seguir". Relembrou que os reagentes ficam a direita da seta enquanto os produtos a esquerda da seta.

Professor: "A equação não é simplesmente uma soma, mas sim uma combinação de átomos, e essas equações obedecem a regra de Lavosier, onde, nada se perde nada se cria, tudo de transforma como o resto da galinha do domingo que não se perde e vira a sopa da segunda... Ou seja toda quantidade de reagentes estará no produto."

Nesse trecho caracterizamos a conduta do professor como bastante efetiva, o professor fez a utilização de acontecimentos corriqueiros sem deixar de lado o conteúdo cientifico, buscando apreender pra si a atenção dos alunos, fazendo com que os mesmos compreendessem com mais facilidade, chegando assim ao seu intuito de adesão dos 
conhecimentos por meio dos alunos, o que pode ser mostrado a partir do trecho da mesma aula, a seguir.

O professor mostrou no quadro a equação seguinte:

\title{
Equaçao 1:
}

\section{$\mathrm{N} 2+3 \mathrm{H} 2 \rightarrow 2 \mathrm{NH} 3$}

E perguntou aos alunos, "Quantos mols de nitrogênio temos nessa equação?”, os aluno ficaram na dúvida dizendo diversos números que achavam que poderia ser e então a maioria concordou que seria 2.

Então, o professor explicou a eles que não poderia ser 2, que como já tinha dito anteriormente o numero que mostra a quantidade do elemento é o coeficiente estequiométrico e se referi-o a ele como "O númerozinho que vem na frente".

Professor: "Quantos mols de Hidrogênio essa equação possui?"

Alunos: "Três"

Professor: "1 mol de nitrogênio $(\mathrm{N})$ mais 3 mols de hidrogênio $(\mathrm{H})$, da quantos mols de NH3?

\begin{abstract}
Alunos: "Dois"
Professor: "Dois? E porque não quatro?... Porque não é a soma e sim as combinações, certo?!"

Percebemos que os alunos participam ativamente das aulas, que o professor busca conduzir os conteúdos de maneira clara e objetiva recorrendo em sua argumentação por problematizações, aproximação com o cotidiano e situações corriqueiras, criação de hipóteses de possíveis duvidas que os alunos podem ter, e comparações, ou seja, com a persuasão e a utilização dessas táticas alcança a adesão possibilitando aos alunos uma apropriação dos conteúdos, uma aceitação e convencimento das ideias, através da condução do conhecimento.
\end{abstract}

\section{Conclusões}

No conjunto de textos que compõem o corpus deste estudo, identificamos nas respectivas aulas uma perspectiva persuasiva do discurso científico, centrada na voz do professor, onde a argumentação persuasiva do docente é evidenciada pelo desenvolvimento da 
produção de significado aos conteúdos abordado durante as aulas. A construção dos conhecimentos é marcada pela produção dos saberes por meio das táticas e interações dialógicas da argumentação persuasiva que o professor proporcionou em busca da adesão, favorecendo o aprendizado dos alunos, desenvolvendo os saberes, conduzindo os estudantes a compreensão e introdução no meio científico. Neste sentido, os resultados apresentados inferem que ao utilizar da argumentação o docente consegue atingir o objetivo por adesão de direcionar os estudantes a compreensão dos conteúdos específicos , contribui também para uma maior interação entre professor-aluno, tornando a sala de aula um ambiente mais agradável.

Com base nessas observações, podemos considerar a importância da utilização das praticas argumentativas nas aulas de química como recurso que possibilita o delineamento do ensino de ciências como um facilitador, de maneira que venha a direcionar e tornar consistente o aprendizado dos conhecimentos científicos dos estudantes.

\section{Referências}

CICILLINI, G. A. A produção do conhecimento biológico no contexto da cultura escolar do ensino médio: a teoria da evolução como exemplo. 1997. 283 f. Tese (Doutorado) Faculdade de Educação, Unicamp, Campinas, SP, 1997.

CORACINI, M. J. R. F. Um fazer persuasivo: o discurso subjetivo da ciência, São Paulo: Educ; Campinas, SP: Pontes, 1991.

GOULART, C. Enunciar é argumentar: analisando um episódio de uma aula de história com base em Bakhtin. Pró-Posições, v. 18, n. 3 (54), p. 93-107, set.-dez. 2007.

JIMÉNEZ-ALEIXANDRE, M. P.; BROCOS, P. Desafios metodológicos na pesquisa da argumentação em ensino de ciências. Ensaio Pesquisa em Educação em Ciências, v. 17, n. especial, p. 139-159, 2015.

LIRA, M. A argumentação em aulas de ciências do ensino fundamental: a persuasão na construção do discurso científico na escola. Tese de Doutorado. Universidade Federal de Pernambuco, 2017.

MASSMANN, D.; a arte de argumentar na sala de aula letras, santa maria, v. 21, n. 42, p. 363-385, jan./jun. 2011.

MENDONÇA, P. C. C. et al. Ensino-aprendizagem de ciências e argumentação : discussões e questões atuais. Revista Brasileira de Pesquisa em Educação em Ciências, v. 1, p. 187216, 2013. Disponível em: 〈http://revistas.if.usp.br/rbpec/article/viewArticle/500〉 
NASCIMENTO, V. B. do. A natureza do Conhecimento Científico e o Ensino de Ciências. In: CARVALHO, A. M. P. (org) Ensino de Ciências: Unindo a Pesquisa e a Prática, São Paulo: Cengage Learning, 2010.

PERELMAN, C.; OLBRECHTS-TYTECA, L. Tratado da argumentação: a nova retórica [1958]. Tradução de Maria Emantina Galvão. São Paulo: Martins Fontes, p. 2-54, 2014.

SANTOS, W. L. P. dos; SCHNETZLER, R. P. Função social: O que significa ensino de Química para formar cidadão? Revista Química Nova na Escola, São Paulo, n. 4, p. 28-34, nov., 1996.

SASSERON, L. H. A construção de argumentos em aulas de ciências: o papel dos dados, evidências e variáveis no estabelecimento de justificativas. In: ENCONTRO NACIONAL DE DIDÁTICA E PRÁTICAS DE ENSINO (ENDIPE), 16., 2012, Campinas, SP. Anais... Campinas, SP, 2012.

SCARPA, D. L. O papel da argumentação no ensino de ciências: Lições de um workshop. Ens. Pesqui. Educ. Ciênc. (Belo Horizonte) vol.17 no.spe Belo Horizonte Nov. 2015.

TEIXEIRA, F. M. É possível argumentação sem controvérsia? Revista Ensaio, Belo Horizonte, v. 17, n. especial, p.187-203, nov. 2015. 